\title{
Preferências por Características do Futuro Filho Adotivo Manifestadas por Pretendentes à Adoção
}

\author{
Isabela Dias Amim \\ Paulo Rogério Meira Menandro \\ Universidade Federal do Espírito Santo
}

\begin{abstract}
RESUMO
A pesquisa objetivou analisar preferências de pessoas cadastradas para adoção quanto às características da criança que pretendiam adotar. Os resultados obtidos confirmam dados disponíveis na literatura que apontam que brasileiros postulantes à adoção preferem crianças recém-nascidas, do sexo feminino, de cor de pele branca. A pesquisa também revelou a ocorrência de mudanças de opinião quanto às preferências por determinadas características do filho adotivo durante o período de espera pela adoção, mudanças estas que em geral se dão no sentido de ampliar as possibilidades de adoção e diminuir o tempo de espera. A partir do trabalho foi possível apresentar perspectivas de atuação para profissionais que trabalham com postulantes à adoção, pois, mais que um trabalho de avaliação, o trabalho com os futuros pais adotivos deve ser de preparo e orientação, no sentido de dar suporte ao grupo familiar, de orientá-lo quanto ao processo de adoção e, principalmente, de abrir espaço para a discussão dos tabus que envolvem a adoção.
\end{abstract}

Palavras-chave: adoção; adoção legal; características preferidas da criança a ser adotada.

\section{ABSTRACT \\ Preferred Characteristics of Future Adopted Children Manifested by Prospective Adoptive Parents}

The objective of this research was to analyze the preferences of people who have signed up for adoption concerning characteristics of the prospective adopted child. The collected results confirm available literature data which point out that Brazilian candidates for adoption prefer newborn Caucasian girls. The findings also showed the occurrence of changes in the opinion about the preferences for determinate characteristics of the adoptive child during the waiting period before adoption, changes that, in general, occur in such an order as to widen the possibilities of adoption and decrease the waiting period. From this work it was possible to present perspectives of action for professionals who work with prospective adoptive parents, since, more than simply evaluation, the work with future adoptive parents should be towards preparation and guiding. Specifically, by providing support to the familial group, guiding with respect of the adoption process, and, mainly, creating and open environment for the discussion of taboos involved in adoption.

Keywords: adoption; legal adoption; preferred characteristics of the prospective adoptive child.

O presente relato está baseado em investigação mais abrangente que objetivou construir um panorama das adoções realizadas através do Juizado da Infância e da Juventude do município de Vila Velha - ES, ressaltando a diversidade de interesses e de interessados envolvidos no processo de adoção. Na pesquisa matriz foram investigadas as variáveis relativas à caracterização das pessoas interessadas em adotar, motivos mencionados para a adoção, preferências quanto às características das crianças desejadas, posição dos pretendentes sobre a revelação à criança de sua natureza adotiva, negociação de casais sobre a adoção, restrições ou preconceitos percebidos pelos adotantes em relação ao seu interesse, entre outras. Apresenta-se aqui um recorte com foco na análise das manifestações dos candidatos à adoção quanto às características da criança que prefeririam adotar.

A palavra adoção (ou adotação) provém do latim adoptatio, e associa-se a considerar, olhar para, escolher, perfilhar (Weber, 1999). Houaiss (2001) situa a origem da palavra no século XV. Registros disponíveis indicam que a adoção é praticada a muitos séculos, assumindo diferentes significados, características e objetivos ao longo da história e em diferentes culturas. Apesar de haver registros de adoção desde a antiguidade, Weber (2001) afirma que a adoção começou 
realmente a adquirir um sentido mais social, voltandose aos interesses do adotando, após a Primeira Guerra Mundial, com o grande número de crianças órfãs e abandonadas.

Gomide (1999) afirma que a adoção no Brasil foi tratada tradicionalmente como via de mão única, ou seja, buscava-se apenas atender aos anseios de adotantes. Tal forma de adoção, conhecida como adoção clássica, é freqüentemente motivada por infertilidade ou esterilidade, e nela elege-se como adotado preferencial o recém-nascido com as mesmas características físicas dos adotantes (imitando uma família biológica), visando solucionar dificuldades de casais sem filhos. A partir do Estatuto da Criança e do Adolescente (ECA) passou-se a privilegiar também o adotado, sendo priorizada a busca de famílias para as crianças e adolescentes em estado de abandono. Assim, passou a ser enfatizada a adoção moderna, que abrange a adoção tardia, inter-racial, de grupos de irmãos, entre outros, buscando solução para dificuldades da criança sem família.

Ebrahim (2001a) assinala que tem se difundido bastante uma cultura da adoção, em que o objetivo é proporcionar um lar para crianças que não o têm, sem valorizar em demasia características como condições de saúde, cor, gênero e idade da criança ou adolescente a ser adotado. Não obstante, permanece como maior interesse, no Brasil, a adoção de bebês. Enquanto muitas crianças maiores continuam sem família, os candidatos à adoção registram pleitos de crianças pequenas, ficando as crianças maiores à espera de pais, e os futuros pais à espera de bebês.

Desde 1990 a adoção legal, no Brasil, é regulamentada pelo ECA e tem como principal objetivo encontrar uma família para crianças e adolescentes abandonados (ou afastados da família em decorrência de violação de seus direitos), tentando adequar a tal objetivo o interesse de pessoas que querem adotar. Atualmente, a pessoa ou casal que se cadastra em um Juizado com interesse em adotar legalmente uma criança ou adolescente tem a possibilidade de, ao preencher o Cadastro de Adoção, escolher algumas características da criança ou adolescente que deseja adotar, como sexo, cor de pele, idade e aspectos de saúde. Os considerados aptos para adotarem aguardam em fila por ordem de inscrição, até chegar sua vez de adotar e até que esteja disponível uma criança ou adolescente adequada ao seu interesse. Em geral o tempo de espera pela adoção é longo (às vezes alguns anos), e isso se deve, principalmente, ao fato de muitos brasileiros interessados em adotar preferirem recém-nascidos brancos (características que não correspondem à maio- ria das crianças disponíveis para adoção - que não são recém-nascidas e geralmente têm cor de pele identificada como parda ou negra). Quando há uma criança com as características apontadas pelos interessados, eles são convidados a conhecê-la. Havendo interesse na adoção daquela criança (o que não é obrigatório, permanecendo o adotante na fila de cadastro quando não houver interesse), será iniciado um estágio de convivência (passível de dispensa), e será iniciado o procedimento legal de adoção, que finaliza com a sentença do juiz e a confecção de novo registro civil.

Como afirma Ebrahim (2000), não existem pessoas sem desejos ou preferências, mas é possível desmistificar certas idéias errôneas acerca da adoção, sem impor aos adotantes crianças que eles não são capazes de aceitar e acolher. Quando os pais adotivos não estão preparados para lidar com o filho, há probabilidade alta da criança por eles adotada ser rejeitada, particularmente se a adoção for tardia, de crianças de cor de pele diferente da dos pais adotivos, ou de crianças doentes ou deficientes. Para a criança que já viveu uma história de abandono, correr o risco de ser novamente rejeitada é situação muito grave. Por outro lado, Diniz (1991) lembra que colocar uma pessoa que deseja adotar perante um caso que ele provavelmente recusará é ato agressivo por parte do técnico judiciário que o fizer, pois a recusa implicará conseqüências negativas para a pessoa que, de resto, está em situação de dependência do Serviço para poder realizar o desejo de ter um filho.

Weber (1999) registra que ocorrências de adoções tardias, de crianças pardas e negras, e de crianças portadoras de necessidades especiais são escassas no Brasil, embora sejam especialmente necessárias por envolverem crianças e adolescentes estigmatizados como inadotáveis. Segundo Ebrahim (2001b), considera-se uma adoção tardia quando a criança tem idade acima de dois anos. A mesma autora afirma que, em geral, só as crianças com até três anos conseguem colocação em famílias brasileiras, restando às mais velhas uma eventual adoção por estrangeiros ou a permanência nas instituições (Ebrahim, 2001a). Segundo dados coletados em São Paulo pelo Centro de Capacitação e Incentivo à Formação de Profissionais, há 36 pretendentes à adoção para cada criança de 0 a 2 anos; cinco pretendentes para cada criança de 2 a 5 anos; duas crianças de 5 a 7 anos para cada pretendente; 13 crianças de 7 a 10 anos para cada pretendente; e 66 crianças com mais de 10 anos para cada pretendente à adoção (Mendonça e Fernandes, 2004).

Ebrahim (2001a) assinala que pesquisas revelam que a maior parte da população brasileira apresenta preconceitos quanto à adoção tardia, como o medo de 
ter dificuldades na educação, apoiado na alegação de que uma criança maior poderia não aceitar os padrões estabelecidos pelos pais adotivos por já terem iniciada sua formação social. Tais pesquisas indicam ainda 0 receio de adotar crianças institucionalizadas pelos maus hábitos que trariam. Assinalam também a crença de que crianças que não sabem que são adotivas têm menos problemas, e por isso deve-se adotar bebês para que se possa esconder delas a adoção. Alvarenga (1999) ressalta que algumas pessoas interessadas na adoção se sentem ameaçadas com a possibilidade de adotar uma criança marcada por privações e pela institucionalização, ou com fortes lembranças dos pais biológicos.

Ebrahim (2000) sustenta que as adoções de crianças maiores são perfeitamente viáveis, e sua concretização e manutenção dependem, entre outros aspectos, da história da criança, do fato dela desejar ou não a adoção, e das ações dos pais adotivos e dos que os cercam. Alvarenga (1999) argumenta que, por já ter vivido experiência de abandono da qual muitas vezes se lembra, a criança mais velha será mais ativa no processo, podendo adotar ou não os pais adotivos como pais.

No Brasil, adoções de crianças pardas e negras são minoritárias (Weber, 1999). Estudo de Weber (2003) sobre desejos e expectativas de pessoas cadastradas para adoção no Juizado da Infância e da Juventude de Curitiba evidenciou que $67 \%$ dos adotantes impõem como condição principal uma criança branca (95\% dos adotantes eram brancos), 19\% dizem aceitar uma criança até morena, ou seja, preferem uma criança branca, mas aceitam uma morena clara, e 7\% dizem não ter preferência quanto à cor da criança. Outra pesquisa com pais adotivos de todo o país, constatou $31 \%$ de pais brancos com filhos adotivos pardos, e só 4,5\% com filhos negros (Weber, 1999).

Embora qualquer adoção em que as características físicas da criança adotada difiram das características dos pais adotivos seja inter-racial, no Brasil o termo é usado quase sempre para as adoções de crianças pardas e negras, visto que a maioria absoluta das pessoas interessadas em adotar pela via legal são brancas. Weber (1999) afirma que apenas 5\% dos brasileiros realizam adoções inter-raciais desse tipo, em sua grande maioria de crianças pardas, enquanto $44 \%$ das adoções realizadas por estrangeiros envolvem crianças brasileiras pardas e $12 \%$ crianças negras (é certo que características das adoções realizadas por estrangeiros refletem o perfil de crianças e adolescentes adotáveis que são disponibilizados para tal grupo de potenciais adotantes).
Egbert e LaMont (2004) investigaram a percepção acerca da preparação dos pais para a adoção de uma criança considerada de difícil colocação em família substituta, quer seja por idade, cor de pele, pertencimento a grupo de irmãos, história pregressa (existência de abuso físico ou sexual, negligência, ou de adoções anteriores mal sucedidas), problemas emocionais e comportamentais, ou outros fatores, a partir da perspectiva dos próprios pais que realizaram esse tipo de adoção. Foram percebidos alguns fatores que contribuíram para que os pais se sentissem mais preparados para a adoção que realizaram, dentre eles o conhecimento da história pregressa da criança, o fato de estar ciente da existência de problemas emocionais ou comportamentais, a existência de experiência anterior com crianças com características similares à que foi adotada (ter adotado previamente ou ter contato com outras crianças adotivas, ou com crianças próximas, como familiares, com as mesmas necessidades), ter mais experiência de vida e maior potencial de maturidade (aspecto associado pelas autoras à idade, de modo que quanto mais velhos os pais adotivos, mais preparados eles se sentiram para a adoção), ter uma boa relação com a agência de adoção e receber treinamento e informação adequados, tanto antes como após a adoção.

A partir da já mencionada pesquisa com pais e filhos adotivos de todo o Brasil, Weber (2003) não constatou problemas no processo adotivo em função da cor da pele ou da idade da criança adotada, o que questiona a concepção mais comum que associa a diferença de cor de pele entre pais e filhos adotivos ou a idade avançada da criança no momento da adoção como possíveis fontes de problemas. Os casos em que foram relatados problemas no processo adotivo estavam mais relacionados à revelação tardia da adoção para a criança do que a outros fatores.

O trabalho de preparação e apoio aos adotantes e às famílias adotivas, especialmente nas adoções interraciais, tardias, e de crianças com necessidades especiais, tem sido feito pelas Associações e Grupos de Apoio à Adoção que existem no Brasil. Tais associações, em geral, não têm fins lucrativos, e seus membros, muitas vezes pais adotivos, trabalham voluntariamente para divulgar a adoção, prevenir o abandono, preparar adotantes, acompanhar pais adotivos, encaminhar crianças para adoção e conscientizar a população sobre a adoção. De acordo com Mendonça e Fernandes (2004), o trabalho nos grupos de apoio contribui também para uma mudança de opinião quanto às características da criança que se deseja adotar. Um exemplo disso é que, em geral, apenas $4 \%$ dos pretendentes entram nos grupos dispostos a levar para casa 
uma criança maior de 4 anos, e ao fim dos encontros, cerca de $20 \%$ dos pretendentes já concordam com essa idéia.

O tema adoção engloba uma série de discussões e grande variedade de interesses. Na presente investigação a proposta foi a de analisar as preferências de pessoas cadastradas para adotar quanto às características da criança que pretendiam adotar, buscando contribuir para a compreensão dos aspectos envolvidos na escolha de tais características. A escolha das características do filho adotivo é processo que, em razão de questões históricas ligadas aos ideais de família, exige pensar considerando estereótipos e preconceitos, podendo as pesquisas contribuir para questionar preconceitos e concepções tradicionais referentes ao tema. Os dados obtidos fornecem elementos para planejar perspectivas de atuação profissional, em especial para psicólogos judiciários que trabalhem com postulantes à adoção. Além de avaliação psicológica, o trabalho com os futuros pais adotivos deve ser de preparo e orientação, no sentido de dar suporte ao grupo familiar, de orientá-lo quanto ao processo de adoção e, principalmente, de abrir espaço para a discussão dos tabus que envolvem a adoção.

\section{MÉTODO}

\section{Participantes}

Participaram da pesquisa pessoas interessadas em adotar crianças ou adolescentes cadastradas no Juizado da Infância e da Juventude de Vila Velha - ES. Foram feitas 21 entrevistas, individuais ou com casais. Os participantes foram convidados à participação na investigação na própria Vara de Família, informados do objetivo da investigação, tendo sido esclarecido que a pesquisa constituía atividade independente do processo de adoção em curso, com o que as informações que prestassem e as opiniões que manifestassem (assim como a eventual decisão de não participar) não teriam qualquer repercussão sobre o referido processo. Em dois casos de entrevistas com casais um dos cônjuges não pode comparecer, de modo que a entrevista foi feita com apenas um deles, que forneceu informações sobre o casal. Desse modo, o grupo de participantes compôs-se de: 12 casais, duas pessoas casadas que forneceram informações sobre ambos os cônjuges, seis pessoas solteiras, uma separada, totalizando 33 participantes (18 mulheres e 15 homens). Na apresentação e análise dos dados foram contabilizados 35 participantes, incluindo as duas pessoas que não puderam comparecer às entrevistas, mas sobre as quais foram obtidas informações por meio de seus cônjuges. As entrevistas foram realizadas nas dependências da
Vara de Família, com a devidamente autorização da autoridade judiciária, e após assinatura de termo de participação voluntária e esclarecida.

A escolha dos participantes não foi aleatória. Tendo em vista que a pesquisa matriz objetivou explorar a diversidade de interesses e interessados envolvidos no processo adotivo, os participantes foram selecionados de forma a englobar ampla diversidade de casos que ilustrassem diferentes especificidades em relação aos vários aspectos da adoção. Tal modalidade de seleção de participantes reduz o alcance de generalização dos resultados, mas foi condizente com os objetivos da pesquisa matriz e, ao invés de limitá-la, abriu a possibilidade de produção de uma riqueza de informações que dificilmente seria alcançada com outra estratégia.

\section{Procedimento e Instrumento}

Foram realizadas entrevistas apoiadas em roteiro semi-estruturado, com o objetivo de coletar informações acerca de vários aspectos da adoção, como tempo de espera desde o cadastramento para adoção, motivos alegados para a pretensão de adotar, eventuais casos de adoção na família, preferências quanto às características das crianças desejadas, expectativas sobre como a adoção pode alterar a vida dos adotantes, posição dos pretendentes quanto a revelar à criança sua condição adotiva, restrições ou preconceitos percebidos pelos adotantes em relação ao seu interesse em adotar, entre outros. O roteiro da entrevista com casais continha questões adicionais àquelas constantes do roteiro da entrevista realizada individualmente com solteiros ou separados, questões estas referentes à negociação do casal em relação a diferentes aspectos da adoção. No relato que aqui se apresenta foram analisadas as informações acerca das preferências dos adotantes quanto às características que gostariam que estivessem presentes nas crianças que desejam adotar.

Além das entrevistas, foi preenchida uma ficha (individual ou referente ao casal) com dados sóciodemográficos (sexo, idade, endereço, escolaridade, estado civil, profissão) e o registro, pela entrevistadora, da cor da pele dos participantes. No caso dos casais também foi registrado o tempo de união.

\section{RESULTADOS E DISCUSSÃO}

A Tabela 1 resume os principais resultados obtidos quanto às preferências das características do filho adotivo. 
TABELA 1

Preferências Quanto às Características da Criança a ser Adotada e Mudanças de Opinião quanto a essas Preferências

\begin{tabular}{|c|c|c|c|c|c|c|c|c|c|c|c|c|c|}
\hline \multirow[b]{2}{*}{ Entrevistas } & \multirow[b]{2}{*}{ Estado civil / cor de pele } & \multicolumn{3}{|c|}{ Sexo preferido } & \multicolumn{3}{|c|}{ Cor preferida } & \multicolumn{3}{|c|}{ Idade preferida } & \multicolumn{3}{|c|}{$\begin{array}{l}\text { Mudou de opinião sobre as } \\
\text { seguintes características preferidas } \\
\text { no filho adotivo: }\end{array}$} \\
\hline & & Menina & Menino & Branco & Pardo & Negro & $\begin{array}{l}\text { Recém- } \\
\text { nascido }\end{array}$ & $\begin{array}{l}\text { Até } 1 \\
\text { ano *3 }\end{array}$ & $\begin{array}{l}\text { Entre } \\
1 \text { e } 3 \\
\text { anos *3 }\end{array}$ & $\begin{array}{c}\text { Acima } \\
\text { de } 3 \\
\text { anos *3 }\end{array}$ & Sexo & Cor & Idade \\
\hline 1 & Casal/parda com branco & & & $x$ & $x$ & & $x$ & $x$ & $x$ & & & & \\
\hline 2 & Casal/branca com negro & $x$ & & & & & & & $x$ & $x$ & & $x$ & $x$ \\
\hline 3 & Solteiro/branco & & $x$ & $x$ & $x$ & & $x$ & $x$ & & & & & \\
\hline 4 & Solteira/branca & $x$ & & $x$ & $x$ & & & & & $x$ & & & $x$ \\
\hline 5 & Casal/branca com pardo & & & & & & $x$ & $x$ & $x$ & & & & \\
\hline 6 & Casal/branca com branco & $x$ & & $x$ & & & $x$ & $x$ & & & & & $x$ \\
\hline 7 & Solteira/parda & $X * 1$ & & $X * 1$ & & & & & $X * 1$ & & & & \\
\hline 8 & Casal/negra com branco & & & & & & $x$ & $x$ & $x$ & & & $x$ & $x$ \\
\hline 9 & Casal/branca com branco & & & $x$ & & & $x$ & & & & & & \\
\hline 10 & Casal/branca com branco & & $x$ & $x$ & & & $x$ & & & & & & \\
\hline 11 & Solteira/branca & $x$ & & & & & $x$ & $x$ & $x$ & & & & \\
\hline 12 & Casal/branca com pardo & & & & & & $x$ & $x$ & $x$ & & & & \\
\hline 13 & Casal/parda com negro & $X * 2$ & & & $X * 2$ & & & & & $X * 2$ & & & \\
\hline 14 & Casal/parda com pardo & & & $x$ & $x$ & & $x$ & $x$ & $x$ & & & & \\
\hline 15 & Solteira/branca & $x$ & & $x$ & $x$ & & $x$ & $x$ & $x$ & $x$ & & $x$ & $x$ \\
\hline 16 & Solteira/parda & $x$ & & $x$ & $x$ & & $x$ & $x$ & $x$ & & & & $x$ \\
\hline 17 & Solteiro/branco & $x$ & & $x$ & $x$ & & $x$ & $x$ & $x$ & & & & \\
\hline 18 & Casal/branca com branco & & $x$ & & & & $x$ & & & & & & \\
\hline 19 & Casal/parda com pardo & $x$ & & & $x$ & & $x$ & $x$ & & & & & \\
\hline 20 & Casal/branca com pardo & & & & & & $x$ & $x$ & $x$ & $x$ & & & \\
\hline 21 & Casal/branca com negro & $x$ & & & & $x$ & & & $x$ & $x$ & & & \\
\hline
\end{tabular}


Das características da criança adotiva a serem escolhidas pelos participantes, foram abordadas mais especificamente sexo, idade e cor de pele. É importante ressaltar que em duas entrevistas (7 e 13) os participantes afirmaram ter interesse na adoção de crianças específicas e, portanto, as características apontadas por eles como preferidas foram as características daquelas crianças que eles desejavam adotar (entrevista 7: menina, 1,2 anos, branca; entrevista 13: menina, parda, 4 anos).

Quanto ao sexo do filho adotivo, os entrevistados disseram não ter preferências em sete das 21 entrevistas, sendo que nesses sete casos as entrevistas foram realizadas com casais. Em cinco desses casos a criança adotiva seria o primeiro filho do casal, e essa foi a razão alegada para não escolher o sexo da criança. Nos outros dois casos, em um a mulher estava grávida de uma menina; e no outro o casal já tinha uma filha adotiva, mas mesmo assim esses casais preferiram não escolher o sexo do próximo filho. Em apenas um desses sete casos (entrevista 8) o casal decidiu abrir mão de preferências pois havia discordância quanto ao sexo preferido (ele preferia menino e ela menina), tendo sido esse o único caso de discordância entre os cônjuges.

Alguns participantes dizem que a opção por não escolher o sexo da criança guarda similaridade com o que ocorre no processo de gestação, visto que não é possível escolher o sexo da criança quando se tem um filho biológico. Desse modo, assim como durante a gestação, os postulantes à adoção experimentam a expectativa de não saber qual será o sexo do filho.

"Não temos preferência por sexo, o que Deus mandar tá bom... é bom que a gente fica na expectativa (risos)." (mulher, casada, 24 anos)

"Não importa se é menino ou menina, nem o filho genético não se pode escolher... então não pode ficar escolhendo muito." (homem, casado, 34 anos)

Nas 14 entrevistas em que se afirmou preferência quanto ao sexo do filho adotivo, sete foram realizadas com casais e sete com os solteiros ou separados. Em 11 casos a preferência era por meninas e em três por meninos. Nota-se preferência muito maior pelo sexo feminino, tal como relatado em várias outras investigações (mencionadas, por exemplo, em Costa \& Campos, 2003). Àqueles que responderam ter preferências por um determinado sexo, foi solicitado que falassem sobre os motivos dessa preferência.
Entre os adotantes solteiros ou separados a justificativa mais freqüente para a escolha do sexo da criança relacionava-se ao seu próprio sexo (será mais fácil ter afinidade, por ser daquele mesmo sexo). Isso ocorreu em cinco dos sete casos. Em um caso o interesse estava relacionado à afinidade com uma criança específica com a qual havia estabelecido contato (criança do mesmo sexo que a adotante). No caso restante, um homem declarou preferência por menina por vontade da mãe dele.

Entre os sete casais adotantes que manifestaram preferências por sexo do adotado, cinco preferiam adotar meninas. Esses cinco casais apresentaram seis razões distintas para a preferência: vontade do filho que não queria dividir brinquedos; inexistência de meninas na família do marido; pelo fato da mulher só ter filho homem; para fazer companhia à filha; porque sempre sonharam com menina; por afinidade com criança específica. Nos dois casos de preferência por meninos estava em pauta o fato de os cônjuges (separadamente) já terem filhas e a vontade dos outros filhos do casal.

Percebe-se que algumas das motivações apresentadas para a preferência pelo sexo do filho adotivo foram muito particulares. Em geral as motivações apontadas para preferência por meninas ou meninos foram similares, e apenas um motivo citado - dizem que menina é mais fácil de criar - ressaltou diferenciação entre os sexos. De acordo com Abreu (2002), no Brasil o sexo masculino parece associar-se a dificuldades no que se refere à educação, o que não acontece em outros países (França, por exemplo). Costa e Campos (2003) afirmam que a maior procura pelo sexo feminino para adoção no Brasil está relacionada aos estereótipos culturais de gênero, que relacionam o sexo feminino à docilidade, beleza e domesticidade. Essa idéia de que a menina é mais fácil de criar do que menino ganhou força historicamente na medida em que era afirmada uma diferença biológica entre os sexos, pela qual a mulher seria dotada de docilidade e sentimento, qualidades estas negadas ao homem pela natureza. Assim, buscou-se manter a simbologia da mulher como dotada de fragilidade e emoções, como mais fácil de lidar e educar, e do homem como dotado de força e razão, com uma natureza forte que não o tornava submisso aos outros. Essas diferenças culturalmente elaboradas acabaram sendo consideradas naturais, inscritas no biológico, e passaram a ocultar relações de poder, marcadas pela dominação masculina, que mantiveram a separação e a hierarquização entre homens e mulheres (Sousa \& Altmann, 1999). 
Quanto à cor de pele do filho adotivo, em 14 entrevistas houve preferência, e em sete não houve. Nos casais, os cônjuges estiveram sempre de acordo em suas opiniões. Em sete entrevistas foi relatada mais de uma cor preferida, e portanto foram consideradas todas as respostas dadas. Nas 14 entrevistas em que houve preferência pela cor, a preferida foi a branca (11 entrevistas), seguindo-se a preferência pela cor parda (nove entrevistas), e pela cor negra em apenas uma entrevista. Tais dados, de forma geral, estão de acordo com os dados obtidos por Weber (1999) em condições similares, segundo os quais a maioria absoluta dos adotantes coloca como condição principal uma criança branca, alguns aceitam uma criança até morena, e raramente é feita a opção por uma criança negra. A criança negra, na grande maioria das vezes, só não está excluída da preferência dos adotantes quando estes afirmam não ter preferências quanto à cor do filho adotivo (sete casos na presente investigação). Dos casos em que foi relatada preferência pela cor de pele da criança, houve um de preferência por criança negra (entrevista 21). A partir disso, pode-se dizer que, no total de 21 entrevistas, enquanto a criança branca é aceita em 18 casos e a criança parda em 16 casos, em apenas oito casos $(38,1 \%)$ há a possibilidade de adoção de crianças negras, o que é um percentual relativamente alto se comparado a outras pesquisas, como a de Weber (1999), que indica que apenas cerca de $7 \%$ dos postulantes à adoção se mostram abertos à adoção de uma criança negra. É preciso cautela com tal comparação, entretanto, uma vez que o número de participantes da presente pesquisa é pequeno e eles foram escolhidos sem qualquer preocupação com a aleatoriedade.

O único casal que relatou preferência por criança de cor negra é inter-racial (ele negro, ela branca conforme a percepção da entrevistadora e, em tal caso, também conforme auto-referência) e argumentou com o fato de o casal ter uma filha biológica negra e querer que a criança adotada seja parecida com a filha biológica, além de mencionar também a realidade da criança negra ter muito menos chances de ser adotada se comparada às crianças brancas e pardas. Em dois outros casos em que foram apontadas preferências pela cor do filho adotivo o interesse é pela adoção de uma criança específica, o que explica as preferências pela cor das crianças. Nos demais casos em que os entrevistados relataram ter preferências quanto à cor da criança, a motivação para essa preferência é querer que a criança seja parecida com os adotantes, e as justificativas para isso são: evitar que as pessoas façam comentários (citada em três entrevistas), evitar que a criança ou os pais tenham que ficar dando explicações (duas), medo de não saber lidar com a diferença (duas), evitar problemas (uma), para a criança se adaptar melhor à família (uma), minimizar o preconceito (uma), e evitar que a criança questione antes do tempo (uma). De fato, Weber (1999) afirma que uma pessoa que decide adotar uma criança cujas características raciais ou de cor de pele sejam diferentes das suas, tem grande probabilidade de enfrentar preconceitos em dobro no Brasil - pela adoção e pela diferença racial. Afirma ainda que esse desejo de que o filho adotivo se pareça com os pais pode expressar também uma necessidade da família adotiva imitar a família biológica, na qual as características genéticas dos pais são transmitidas aos filhos, resultando razoável semelhança com os pais biológicos. Abreu (2002) assinala que essa opção dos adotantes por criança se pareça com eles tem por objetivo facilitar a identificação dos pais adotivos com os filhos. Segundo ele, os pais buscam, através da adoção, reproduzir socialmente sua continuidade e semelhança, o que ocupa no imaginário social um lugar central na reprodução. Costa e Campos (2003) afirmam ser comum, em estudos psicossociais de adoção, os adotantes mencionarem com orgulho a semelhança dos filhos consigo ou com outros membros da família, pois ressaltar tais semelhanças parece consolidar um vínculo de parentalidade sob ameaça de não existir dada a ausência de ligação biológica.

A cor de pele dos postulantes à adoção tem importante relação com a escolha que eles fazem quanto à cor de pele da criança que pretendem adotar. $\mathrm{Na}$ presente pesquisa a maioria dos participantes tem a pele branca: $57,1 \%$ são brancos, $31,4 \%$ são pardos e $11,4 \%$ são negros. Isso está de acordo com dados obtidos por Weber (1999), segundo os quais a maioria dos adotantes no Brasil é composta por pessoas de pele branca, e apenas uma minoria é negra. Como a adoção, na maior parte dos casos, não é realizada por uma única pessoa, pode ser revelador considerar a informação sobre cor de pele em conjunto com a cor de pele do cônjuge. Dos 14 casais entrevistados, oito são inter-raciais e seis não. Dos casais inter-raciais, quatro são constituídos de branco com pardo, três de branco com negro e um de pardo com negro. Dos casais em que ambos os cônjuges têm a mesma cor de pele, quatro são brancos e dois são pardos. Não houve caso de casal com ambos os cônjuges negros.

Foi feita a comparação da cor de pele daqueles participantes que relataram ter preferências quanto à cor de pele do filho adotivo com as preferências apontadas por eles. Os resultados aparecem na Tabela 2. 
TABELA 2

Comparação da Cor da Pele dos Participantes que Apontaram Preferências pela Cor da Pele do

Futuro Filho Adotivo com as Preferências Relatadas por Eles

\begin{tabular}{|c|c|c|c|}
\hline Entrevistas & Sexo & Cor da Pele dos Participantes & $\begin{array}{l}\text { Preferência pela Cor da Pele } \\
\text { do Filho Adotivo }\end{array}$ \\
\hline \multirow[t]{2}{*}{ Entrevista 1} & $\mathrm{H}$ & Branca & \multirow[t]{2}{*}{ Branca ou Parda } \\
\hline & M & Parda & \\
\hline Entrevista 3 & $\mathrm{H}$ & Branca & Branca ou Parda \\
\hline Entrevista 4 & M & Branca & Branca ou Parda \\
\hline \multirow{2}{*}{ Entrevista 6} & $\mathrm{H}$ & Branca & \multirow{2}{*}{ Branca } \\
\hline & M & Branca & \\
\hline Entrevista 7 & M & Parda & Branca \\
\hline \multirow{2}{*}{ Entrevista 9} & $\mathrm{H}$ & Branca & \multirow{2}{*}{ Branca } \\
\hline & M & Branca & \\
\hline \multirow{2}{*}{ Entrevista 10} & $\mathrm{H}$ & Branca & \multirow{2}{*}{ Branca } \\
\hline & M & Branca & \\
\hline \multirow{2}{*}{ Entrevista 13} & $\mathrm{H}$ & Negra & \multirow{2}{*}{ Parda } \\
\hline & M & Parda & \\
\hline \multirow{2}{*}{ Entrevista 14} & $\mathrm{H}$ & Parda & \multirow{2}{*}{ Branca ou Parda } \\
\hline & M & Parda & \\
\hline Entrevista 15 & M & Branca & Branca ou Parda \\
\hline Entrevista 16 & M & Parda & Branca ou Parda \\
\hline Entrevista 17 & $\mathrm{H}$ & Branca & Branca ou Parda \\
\hline \multirow{2}{*}{ Entrevista 19} & $\mathrm{H}$ & Parda & \multirow{2}{*}{ Parda } \\
\hline & M & Parda & \\
\hline \multirow{2}{*}{ Entrevista 21} & $\mathrm{H}$ & Negra & \multirow{2}{*}{ Negra } \\
\hline & $M$ & Branca & \\
\hline
\end{tabular}

Considerando individualmente os 22 participantes que apontaram preferências quanto à cor de pele do filho adotivo, 54,5\% têm pele branca, 36,4\% têm pele parda e 9,1\% têm pele negra. Em relação às suas preferências (cada participante pôde dar mais de uma resposta), percebe-se que $72,7 \%$ indicam como preferência uma criança branca e 59,1\% indicam uma criança parda, o que significa que não apenas as pessoas brancas preferem ou aceitam adotar crianças brancas, mas também que a adoção de crianças pardas é preferida ou aceita por alguns adotantes brancos.

Percebe-se que, em geral, os entrevistados preferiram crianças de cor de pele semelhante à sua própria cor. No caso de adotantes solteiros, a criança com cor de pele igual à de suas próprias peles sempre está indicada como preferência. Apenas em um caso (entrevista 7) a cor da criança não se assemelha à da adotante, e este é um dos dois casos em que a adoção é motivada por afinidade com uma criança específica, em que a cor de pele da criança não teve influência direta sobre a decisão de adotar. No caso dos casais, preferir uma criança da própria cor significa preferir uma criança da cor de pelo menos um dos cônjuges, visto que a proximidade entre a cor da criança e a cor de pelo menos um dos pais adotivos sinaliza (para o próprio casal e para as demais pessoas com que interage) a possibilidade de se tratar de um filho biológico. Pode-se dizer que, nas adoções realizadas por casais, quando os entrevistados dizem querer uma criança parecida com eles, estão levando em conta a cor de pele de ambos os cônjuges. Percebe-se que há certa tolerância quanto à diferença de cor entre adotantes e adotados, mas tal tolerância tem um limite claro, visto que crianças de pele negra raramente são apontadas como preferidas. Parece que, tanto para pessoas brancas como para pessoas pardas, solteiras ou casadas, a única situação em que o filho adotivo realmente será diferente dos pais é quando ele é negro.

Das entrevistas nas quais se afirmou não haver preferências quanto à cor do filho adotivo (total de 7), uma foi realizada com pessoa solteira de pele branca, uma com casal de brancos, e cinco foram realizadas com casais inter-raciais (em três casos um dos cônjuges é branco e o outro pardo, e em dois casos um dos cônjuges é branco e o outro é negro). Observe-se que apenas para os casais de brancos com negros, o fato 
de não ter preferência em relação à cor do filho adotivo ainda está de acordo com o argumento de querer que os filhos adotivos sejam parecidos com os pais.

Em duas entrevistas as pessoas relataram dificuldade em definir a cor de pele de alguém, pois pessoas diferentes podem discordar sobre a cor de uma pessoa. Um casal com preferência por criança branca ou parda relatou que foi chamado pelo Juizado para conhecer uma criança parda, e quando chegaram ao abrigo avaliaram a criança como sendo negra, e não a adotaram.

\begin{abstract}
"Nós fomos ver a [nome] ... Nós colocamos que a gente quer uma criança de pele branca, até parda, $e$ aí foi a confusão, porque quando nós chegamos, a [nome] para nós ela não era parda, para nós ela era negra mesmo, né, então a gente pegou e ligou e disse assim 'olha, se a [nome] para nós é parda a gente até muda, coloca de cor branca', porque diz que não existe a morena ou moreno, né... O problema é a definição do que é isso, porque é complicado... e aí vai ter que ser na hora de olhar mesmo, de estar com a criança. O pardo vai até onde pra nós e até aonde começa o negro, é a gente que vai definir isso, é muito difícil e até constrangedor..." (homem, casado, 30 anos)
\end{abstract}

Um dado interessante é que em uma das entrevistas foi apontada a necessidade de haver maior incentivo às famílias negras para a adoção legal. Como as crianças disponíveis para adoção, em maioria, são negras, uma entrevistada afirmou ser interessante que famílias negras fossem incentivadas a adotar, para que houvesse proximidade na aparência entre essas crianças e seus pais adotivos, favorecendo a adoção. É preciso considerar que, provavelmente, pessoas negras adotam pouco no Brasil porque na população de baixa renda do país o negro está super-representado, em função de vários aspectos sócio-histórico-políticos. Além disso, essa é uma alternativa que não contribui para o questionamento de preconceitos sociais. Afirmando a necessidade de o filho ser parecido com os pais adotivos, tal alternativa afirma a necessidade de se camuflar a família adotiva, como se ela fosse menos legítima que a biológica.

Em relação à idade do filho adotivo, todos os entrevistados apontaram preferências. Nas entrevistas com casais, não houve discordância entre os cônjuges quanto à idade preferida. Em três entrevistas foi mencionada a exigência da criança ser recém-nascida e em outros 13 casos a criança recém-nascida faz parte da preferência - o que totaliza 16 casos (76,2\%). Entre eles verifica-se preferência por criança entre 0 e 1 ano (seis casos); entre 0 e 1,5 ano (um caso); entre 0 e 2 anos (cinco casos); entre 0 e 3 anos (dois casos); e entre 0 e 4 anos (dois casos). Entre pessoas que não apontaram o recém-nascido como preferência existem dois casos de interesse por crianças específicas (com 1,2 e 4 anos), e três casos em que outras faixas de idade foram apontadas como preferência: de 1 a 5 anos, de 3 a 8 anos, e de 2 a 4 anos.

Só em um caso a preferência engloba crianças entre 5 e 8 anos, não havendo preferência por crianças acima de 8 anos. Assim, a preferência é inversamente proporcional à idade da criança, o que corrobora dados disponíveis em Weber (1999), Ebrahim (2000, 2001a, 2001b) e Mendonça e Fernandes (2004), segundo os quais quanto maior a idade da criança disponível para adoção, mais difícil é que ela entre na preferência dos interessados em adotar e, portanto, mais improvável a concretização da adoção.

Vários foram os motivos relatados para a preferência por idade da criança, e eles variaram conforme a faixa etária preferida. Um dado importante é que muitos entrevistados afirmam que querem bebês, mas varia muito a idade da criança que eles consideram como sendo um bebê. Por exemplo, em uma entrevista os participantes consideram um bebê uma criança de até 6 meses; em outra, bebê seria a criança de até 2 anos; e em uma terceira foi considerada bebê a criança de até 3 anos. Assim, esses três entrevistados apontaram motivos pelos quais gostariam de adotar bebês, mas a idade da criança considerada como sendo um bebê variou de entrevistado para entrevistado.

Dentre as motivações relatadas para a preferência por idade do filho adotivo, a mais ressaltada por aqueles que querem bebês (variando aí a idade que consideram ser a de um bebê) foi querer educar do seu jeito (25\% das respostas). De acordo com Abreu (2002), a preferência por crianças pequenas muitas vezes está relacionada a essa idéia que os adotantes têm do papel da educação que podem dar à criança, educação esta capaz de paliar os problemas genéticos que a criança eventualmente porte. Ou seja, quanto mais cedo uma criança chegar, mais oportunidade terá o adotante de moldá-la. Outras motivações citadas foram: querer que a criança se acostume com eles desde pequena (15,6\% das respostas), querer curtir a fase de bebê (12,5\%), querer passar por todas as etapas da criança $(9,4 \%)$, e por opção de filhos já existentes $(3,1 \%)$.

Dentre os motivos relatados por aqueles que não querem bebês, os motivos ressaltados para o limite inferior de idade foram não querer ter trabalho com 
um bebê (9,4\% das respostas), e querer que a criança já saiba falar/andar (6,3\%), e para o limite superior de idade foram não querer que o filho vá direto para a escola $(3,1 \%)$ e querer passar por uma fase infantil $(3,1 \%)$. Outras motivações para a preferência por idade do filho adotivo foram: querer que os filhos biológico e adotivo tenham idades próximas (6,3\%), e ter afinidade com uma criança específica (6,3\%).

Analisando todas as preferências em relação às características do filho adotivo, constata-se concordância com a literatura que aponta meninas brancas recém-nascidas como o modelo das crianças preferidas para adoção no Brasil (Weber, 1999). Apesar da ausência de indagações diretas sobre a saúde do filho adotivo, tal aspecto foi mencionado em seis entrevistas. Em cinco delas foi relatada a necessidade da criança ser saudável (pela dificuldade de cuidar por ser solteiro em dois casos, por falta de condições emocionais em dois casos, e por falta de condições financei- ras em outro). Em uma entrevista fica claro que o fato da criança ter a saúde comprometida não foi obstáculo para a adoção. Um dado curioso: dois entrevistados disseram que, havendo oportunidade, adotariam gêmeos (um casal em um caso, e duas meninas em outro).

A partir dos dados percebe-se que na totalidade dos casais entrevistados ambos os cônjuges relataram ter a mesma preferência para todas as características do filho adotivo, havendo um único caso em que foi necessária certa negociação para chegar ao acordo - ela preferia menina, ele menino, e optaram por desistir de preferências quanto ao sexo da criança.

Em seis entrevistas constatou-se mudanças de opinião quanto às preferências por determinadas características do futuro filho adotivo. Essas informações podem ser vistas na Tabela 3.

TABELA 3

Mudanças nas Preferências por Características do Futuro Filho Adotivo Durante o Processo de Adoção

\begin{tabular}{|c|c|c|c|c|c|c|}
\hline \multirow[t]{3}{*}{ Entrevistas } & \multicolumn{6}{|c|}{ Mudanças na preferência das características do filho adotivo } \\
\hline & \multicolumn{2}{|c|}{ Sexo } & \multicolumn{2}{|c|}{ Cor da pele } & \multicolumn{2}{|c|}{ Idade } \\
\hline & Antes & Depois & Antes & Depois & Antes & Depois \\
\hline Entrevista 2 & & & Branca ou Parda & $\begin{array}{l}\text { Não tem mais } p \\
\text { por cor de pele }\end{array}$ & $0-2$ anos & $1-5$ anos \\
\hline Entrevista 4 & & & & & 2,5-4 anos & 3-8 anos \\
\hline Entrevista 6 & & & & & $0-3$ meses & $0-8$ meses \\
\hline Entrevista 8 & & & Branca ou Parda & $\begin{array}{l}\text { Não tem mais } p \\
\text { por cor de pele }\end{array}$ & $0-2$ anos & 0-3 anos \\
\hline Entrevista 15 & & & $\begin{array}{l}\text { Não tinha } \\
\text { preferência por cor } \\
\text { de pele }\end{array}$ & Branca ou Parda & $\begin{array}{l}\text { Recém- } \\
\text { nascido }\end{array}$ & 0-4 anos \\
\hline Entrevista 16 & & & & & $0-1$ ano & $0-3$ anos \\
\hline
\end{tabular}

Verifica-se que não houve mudança na preferência pelo sexo do filho adotivo. Em três casos foram relatadas mudanças na preferência pela cor de pele, e em todos os seis alterou-se a preferência pela idade. Dentre os motivos apontados para essa alteração (consideradas todas as respostas dadas - total de sete), destacam-se a participação no grupo de discussão sobre adoção no Juizado da Infância e da Juventude de Vila Velha (cinco casos), a visita feita a abrigos (um caso), e a conversa com amigos sobre adoção (um caso). Vale ressaltar que o tempo de espera do candidato à adoção costuma variar em função de características da criança que quer, sendo que idade e cor de pele influenciam muito mais o tempo de espera do que sexo. No que se refere à preferência dos pais, quanto mais nova é a criança, e quanto mais clara é a cor da sua pele, mais difícil é a adoção (pela indisponibilidade de crianças), e por isso maior é o tempo de espera dos candidatos. Assim, as alterações relatadas pelos participantes, tanto em relação à cor de pele como em relação à idade, se deram no sentido de ampliar as possibilidades de adoção e também de diminuir o tempo de espera.

Segundo Costa e Rossetti-Ferreira (2004), uma das especificidades interessantes do tornar-se pai e mãe por via de adoção é o fato da pessoa ou casal estar em condição que permite fazer escolhas iniciais sobre a criança desejada (como cor, sexo, idade), escolhas estas que não ocorrem num processo de filiação bio- 
lógica. Entretanto essa pessoa ou casal é ao mesmo tempo enredada em processo no qual, de certa forma, passa a ser escolhida pelas circunstâncias, tendo que levar em consideração, por exemplo, o tempo de espera para a adoção e as características físicas das crianças disponíveis, entre outros aspectos. Essas circunstâncias podem modificar a maternidade/paternidade inicialmente idealizada, pois as escolhas alteram-se de modo a se ajustar à maternidade/paternidade possível. Isso pôde ser observado, já que os entrevistados modificaram características preferidas do filho adotivo no sentido de adequar o seu desejo de ser pai/mãe às possibilidades reais de adoção, levando em conta as circunstâncias que interferem na velocidade do processo adotivo.

De todas as mudanças citadas, apenas uma se deu no sentido de reduzir as possibilidades de adoção, que foi a já mencionada mudança na entrevista 15 , pois a entrevistada não tinha preferência por cor de pele, passou a preferir crianças brancas ou pardas, fazendo restrição à criança negra. Segundo a participante, a mudança deve-se a ter ouvido de amigos casos de pessoas que adotaram crianças de cor de pele diferente da própria e tiveram problemas com isso. A partir disso a entrevistada ficou com medo de não saber lidar com uma diferença marcante de cor de pele entre ela (que é branca) e a criança, e passou a fazer restrição à adoção de criança negra.

Sobre o medo de adotar criança de cor de pele diferente, é interessante o relato do casal que já possui uma filha adotiva de 7 anos, e que tem a pele mais escura que a deles (pais adotivos).

\begin{abstract}
"Não fizemos restrição no cadastro... apesar de que com a Luzia, ela é um pouco mais amorenada, né, um pouco mais "jambinho", principalmente quando vai à praia no verão então, nossa, ela fica super morena. E a gente viu que ela se sentia incomodada com isso, ela sempre questionou: por que eu sou tão morena assim e vocês são tão branquelos? Por que eu sou tão morena assim e as minhas priminhas não são? Então a gente viu algum questionamento, e algum sofrimento talvez, por conta dessa diferença, por parte dela. E a gente explica, não filha, mas a sua pele é linda, veja, a gente tem que passar aqui um monte de óleo pra ficar na cor que você tá e você já fica assim natural (risos). Hoje ela não tem mais esse problema não, mas ela teve.”(homem, 34 anos)
\end{abstract}

Apesar de o casal ter percebido o questionamento por parte da filha (que sabia que era adotada) quanto à diferença de cor de pele entre ela e eles, não encara- ram o fato como dificuldade, e o trataram com naturalidade. O casal relata que hoje isso não é mais problema para filha, e que esse é um tipo de obstáculo que pode ser facilmente superado. Esse casal está tentando a segunda adoção, e continua não tendo preferências quanto à cor de pele do filho que será adotado.

Santos (1988) afirma que, quanto à decisão de ter um filho, os pais adotivos têm que atingir um nível a que não precisam chegar, necessariamente, os pais biológicos, pois para adotarem têm que levar adiante uma série de providências e escolhas iniciais, enquanto os pais biológicos podem tornar-se pais sem terem tido tal pretensão e sem terem refletido sobre essa escolha. Os resultados obtidos corroboram as afirmações de Santos (1988), pois indicam que os pais adotivos têm que refletir com mais cuidado e durante mais tempo a respeito de uma série de questões que muitas vezes não se colocam aos pais biológicos, ou não se colocam da mesma forma, dentre elas a escolha das características do filho adotivo. Tal exigência impõe-se mesmo aos adotantes solteiros.

Retoma-se aqui a afirmação de que a escolha das características do filho adotivo caracteriza-se como um processo no qual, em razão de questões históricas ligadas a ideais de família, estão envolvidos estereótipos e preconceitos de adotantes e de técnicos que decidem sobre a adoção, com o que se tornam fundamentais investigações em torno dos preconceitos e das concepções tradicionais em relação ao tema. O psicólogo judiciário, assim como outros profissionais que lidam com postulantes à adoção, conscientes das relações de poder que permeiam seu trabalho, podem tornar-se agentes de mudança, contribuindo para um processo de revisão de conceitos e valores, já que são responsáveis pela realização do trabalho de avaliação com os futuros pais adotivos. Como afirma Oliveira (2002), não se pode ignorar que a avaliação dos pretendentes à adoção resume-se a uma visão pontual, precisa, feita em um momento determinado, já que o profissional tem prazo para cumprir sua tarefa. Além disso, nesse trabalho tem-se apenas uma avaliação das possibilidades que essas pessoas apresentam para desempenhar seus papéis parentais, seus desejos e suas motivações, visto que as figuras parentais e filiais são interdependentes, e não se pode desconsiderar o papel ativo que as crianças exercem nos ajustes das interações. Por isso, mais que trabalho de avaliação, o trabalho com os futuros pais adotivos deve ser de preparo e orientação, no sentido de dar suporte ao grupo familiar, de orientá-lo quanto ao processo de adoção e, principalmente, de abrir espaço para a discussão dos 
tabus que envolvem a adoção. Esse trabalho, como afirma Ebrahim (2001b), pode ser decisivo para que haja mudanças nas próprias formulações dos pedidos dos adotantes, podendo contribuir para alterar o quadro atual de desejo generalizado por um único tipo de criança.

\section{REFERÊNCIAS}

Abreu, D. (2002). No bico da cegonha: Histórias de adoção e da adoção internacional no Brasil. Rio de Janeiro: Relume Dumará.

Alvarenga, L. L. (1999). Adoção e mitos familiares. Em T. FéresCarneiro (Org.), Casal e família: Entre a tradição e a transformação (pp. 164-173). Rio de Janeiro: NAU.

BRASIL. Estatuto da Criança e do Adolescente. Lei N. ${ }^{\circ} 8.069$ de 13 de julho de 1990. Ministério Público do Estado do Espírito Santo e Centro de Apoio Operacional da Infância e Juventude (2001). Estatuto da Criança e do Adolescente (Lei N. ${ }^{\circ} 8.069$ de 13 de julho de 1990) e Legislação Congênere. Vitória: Artgraf.

Costa, L. F., \& Campos, N. M. V. (2003). A avaliação psicossocial no contexto da adoção: Vivências das famílias adotantes. Psicologia: Teoria e Pesquisa, 19(3), 221-230.

Costa, N. R. A., \& Rossetti-Ferreira, M. C. (2004). Negociando sentidos de maternidade e paternidade em diferentes momentos do processo de adoção. Em Z. M. M. Biasoli-Alves (Org.), Livro de artigos - Tomo II (pp. 391-403). Ribeirão Preto: Programa de Pós-Graduação em Psicologia da FFCLRP-USP.

Diniz, J. S. (1991). A adoção: Notas para uma visão global. Em F. Freire (Org.), Abandono e adoção: Contribuições para uma cultura da adoção (pp. 67-83). Curitiba: Terre des Hommes.

Ebrahim, S. G. (2000). As possibilidades da adoção tardia. Psico, 31(1), 171-178.

Ebrahim, S. G. (2001a). Adoção tardia: Altruísmo, maturidade e estabilidade emocional. Psicologia: Reflexão e Crítica, 14(1), 73-80.
Ebrahim, S. G. (2001b). Adoção tardia: Uma visão comparativa. Estudos de Psicologia, 18(2), 29-40.

Egbert, S. C., \& Lamont, E.C. (2004). Factors contributing to parents' preparation for special-needs adoption. Child and Adolescent Social Work Journal, 21(6), 593-609.

Gomide, P. I. C. (1999). Prefácio. Em L. N. D. Weber, Laços de Ternura: Pesquisas e histórias de adoção (2a ed., pp. 17-18). Curitiba: Juruá.

Houaiss, A. (2001). Dicionário Houaiss da língua portuguesa. Rio de Janeiro: Objetiva.

Mendonça, M., \& Fernandes, N. (2004, 23 de agosto). A grande família adotiva. Época, 96-102.

Oliveira, N. G. S. (2002). Padrões de adoção: Reinterpretação à luz de uma perspectiva etológica. Tese de doutorado nãopublicada, Universidade de São Paulo.

Santos, N. P. F. (1988). As possibilidades de satisfação na adoção. Psicologia: Teoria e Pesquisa, 4(2), 113-128.

Sousa, E. S., \& Altmann, H. (1999). Meninos e meninas: Expectativas corporais e implicações na educação física escolar. $\mathrm{Ca}$ dernos Cedes, 19(48), 52-68.

Weber, L. N. D. (1999). Laços de Ternura: Pesquisas e histórias de adoção ( $2^{\mathrm{a}}$ ed.). Curitiba: Juruá.

Weber, L. N. D. (2001). Pais e filhos por adoção no Brasil. Curitiba: Juruá.

Weber, L. N. D. (2003). Aspectos psicológicos da adoção ( $2^{\mathrm{a}}$ ed.). Curitiba: Juruá.

Recebido: 22/03/2007

Última revisão: 09/07/2007

Aceite final: 06/09/2007

Notas:

${ }^{1}$ Apoio: CNPq.

\section{Sobre os autores:}

Isabela Dias Amim: Mestre em Psicologia pela Universidade Federal do Espírito Santo.

Paulo Rogério Meira Menandro: Doutor em Psicologia pela Universidade de São Paulo. Professor do Departamento de Psicologia Social e do Desenvolvimento da Universidade Federal do Espírito Santo.

Endereço para correspondência: Rua Constante Sodré, 869 - apto 201 - Praia do Canto - Vitória/ES - CEP 29055-420 - Endereço eletrônico: paulomenandro@uol.com.br. 